\title{
XIII. On the comparative powers of algebra and vulgar arithmetic
}

\section{William Gutteridge Esq.}

To cite this article: William Gutteridge Esq. (1818) XIII. On the comparative powers of algebra and vulgar arithmetic , Philosophical Magazine Series 1, 52:244, 88-90, DOI: 10.1080/14786441808652011

To link to this article: http://dx.doi.org/10.1080/14786441808652011

册 Published online: 23 Jul 2009.

Submit your article to this journal $\sqsubset \pi$

Џ Article views: 3

Q View related articles $\asymp$ 
while in the Geranium, the pistil is made to bend by the filaments twisting round her! How beantifully does the Spartium junceum throw off its keel, that the pistil may have room to sweep ronnd, and turn its points to the spreading stamens, which pass between each! I have watched this, flower after flower, with admiration : for the manner in which it first throws back the banner is most curious; the wings then fly apart, and the inward motion of the keel becomes perceptible; when the sun striking full on it, it flies open, and the stamens disperse some of their powder. Now at full liberty, the boxes of the stamen open, and the pistil turns round, and one after the other presses between the two points of the stigma, and thus loads it with powder.

I must now stop : My letter is already too long. Fig. 7 is the interior of the flower of the Aquilegia vulgaris, to show how thie hearts of the seeds pass up the stem to the seed-vessel and seeds at $e e e$, and how the juice passes up from the secret nectary $a$ a to the stigma $b b l$, and the pollen up the vessels $g g$ to the stamen $f f$. Fig. 8 is a sirigle pericarpium and stigma at top. Fig. 5 is the interior pillar of the Iris, \&ic. The rest I believe I have already explained.

$$
\text { I am, sir, your obliged servant, }
$$

Agnes IbBetson,

\section{Description of Plate II. No. 8.}

Fig. 9 is the stigma of the Ground Ivy; the pollen powiler within the balls enters the diminutive holes, when dissolved. At $a a$ in

Fig. 4 is one of those stigmas which are so much larger than the style, and have a gutter running round at $a a \alpha$, and descending also at $b b$ to the style.

Fig. $4 \mathrm{X}$ is the stigma of the Pentandria digynia plant; and c $c c$ the hairs at which the mixed juices enter the stigma: it has a gutter all round, and one through the middle.

Fig. 3 is the manner in which the stamens loosely surround the pistil when it is supposed to be fastened to it. B and C two more stigmas.

The seeds, fig. $7 \mathrm{X}$ and fig. $2 c c$ are the shape of the seeds at that time, both impregnated.

XIII. On the Comparative Powers of Algebra and Vulgar Arith melic. By William Gutperidge, Esq.

$$
\text { To Mr. Tilloch. }
$$

Sin,-As you will no doubt acknowledge that in a commercial cuuntry like ours, the true principles of calculation should be 
thoroughly understood and profoundly taught, I feel persuaded that you will permit me, through the medium of your Magazine, to express my disapprobation of the present method, which prevails in the public seminaries throughout the united kingdom, of solving such questions as relate to mixing of merchandises, as rums, wines, \&c. commonly termed Alligation, which, save the medial case, is in all respects very abstruse, frequently false, and generally detrimental to the merchant. Nay nore, indeterminate equations (of which questions in Alligation are a species) are in works of the greatest celebrity very frequently most erroneously solved, where the great power of algebra in the present mode of application is insufficient to demonstrate the truth: whilst, if rightly handled, vulgar arithmetic is abundartly sufficient to obtain all the integral answers to such questions.

That this is not on my part a mere assertion, but a wellgrounded fact, I shall adduce, for the satisfaction of the public, a most glaring instance, which may be found in that well-known work, Dedson's Mathematical Repository, where, vol. ii. question XII. page 39, we read as follows:

"Let $2 x+3 y+5 z+30 u=100003$," the number of integral answers (see fol. 44) are stated to be " $160,190,378,249 . "$

Now, sir, you will give me leave to state, that the actual number of integral equivalent answers to that equation are just $185,090,752,407$; therefore the error in Dodson's computation is 24,900,374,158 answers ton few. And you will also give me leave to state, that such erroneons computation arises not from accident, but from the adopted method of solution.

Authors have uniformly avowed that vulgar arithmetic wouls not obtain all the possible answers to questions of this sort, and that algebraic reasoning was indispensable. I am ready to prove the contrary, and to show that arithmetic is not only equal, but infinitely superior, in all cases of alternation.

Errors equally glaring are to be found in the algebra of the celebrated Bonnycastle, who, so recently as his 7 th edition of that great art, fails in some of these equations. And, what is more extraordinary, the ingenious $M r$. Davis's Key to that celebrated work corresponds with the author's errors;-a proof of the necessity of adopting a different system, whereby the truth may bo discovered.

To enter into sufficient detail would engross too many pages of your Magazine; for I am well aware, that in instances where errors have become habitual, nothing short of an elaborate pron cess can possibly convince. I shall therefore content myself, for the present, with a general disapproval of the inadequacy of that system universally prevailing; but should any gentleman 
think proper to dispute the accuracy of my foregoing computation, or the justice of my disapproval, (and that you will be pleased to afford me your pages as the medium,) I shall enter without hesitation into all the minutiæ of the question.

I am, sir,

Your most obedient servant,

St. Finbars, Cork, July 15, 1818.

William GutTeridge.

XIV. An Account of Experiments for determining the Length of the Pendulum vibrating Seconds in the Latitude of London. By Capt. Henry Kater, F.R.S.*

T.

o determine the distance between the point of suspension and centre of oscillation of a pendulun vibrating seconds in a given latitude, has long been a desideratum in science. Many experinents have been made for this purpose ; but the attention of all who have hitherto engaged in the inquiry (excepting Whitehurst) appears to have been directed to the discovery of the centre of oscillation. The solution of this problem depending, however, on the uniform density and known figure of the body employed, (requisites diffieult if not impossible to be ensured in practice,) it is not surprising that the experiments made by different persons should have been productive of various results.

When I had the honour of being appointed one of the committee of the Royal Society for the investigation of this interesting subject, I imagined that the least objectionable mode of proceeding would be to employ a rod drawn as a wire, in which, supposing it to be of equal density and diameter throughout, the centre of oscillation, as it is well known, would be very nearly at the distance of two-thirds of the length of the rod from the point of suspension; and I purposed by inverting the rod, and taking a mean of the results in each position, to obviate any error which might arise from a want of uniformity in density or figure. After numerons trials however, and as frequent disappointments, I was at length convineed of the impracticability of obtaining a rod sufficiently uniform; and I was besides aware, that under certain circumstances errors might arise from this cause which it would be impossible by any method to detect.

Not feeling at all satisfied with the prospect which the use of a rod presented, I endeavoured to discover some property of the pendulum of which I might avail myself with greater probability of success; and I was so fortunate as to perceive one, which

* From the Transactions of the Royal Society for 1818, part $i$. 